\title{
Metatarsal Bone Digit 5
}

National Cancer Institute

\section{Source}

National Cancer Institute. Metatarsal Bone Digit 5. NCI Thesaurus. Code C52787.

The fifth of the five long bones located in the mid-foot, which articulates proximally with the cuboid bone at the tarsometatarsal joint and distally with the metatarsophalangeal joint. 